\title{
CAMPUR KODE BAHASA JAWA BANYUMASAN DALAM PEMBELAJARAN BAHASA INDONESIA DI SEKOLAH MENENGAH KEJURUAN
}

\author{
Bekty Tandaningtyas Sundoro, Sarwiji Suwandi, dan Budhi Setiawan \\ Universitas Sebelas Maret, Surakarta \\ Jalan Ir. Sutami Nomor 36A, Jebres, Surakarta, Jawa Tengah \\ Surel: tyas.bekty@ gmail.com
}

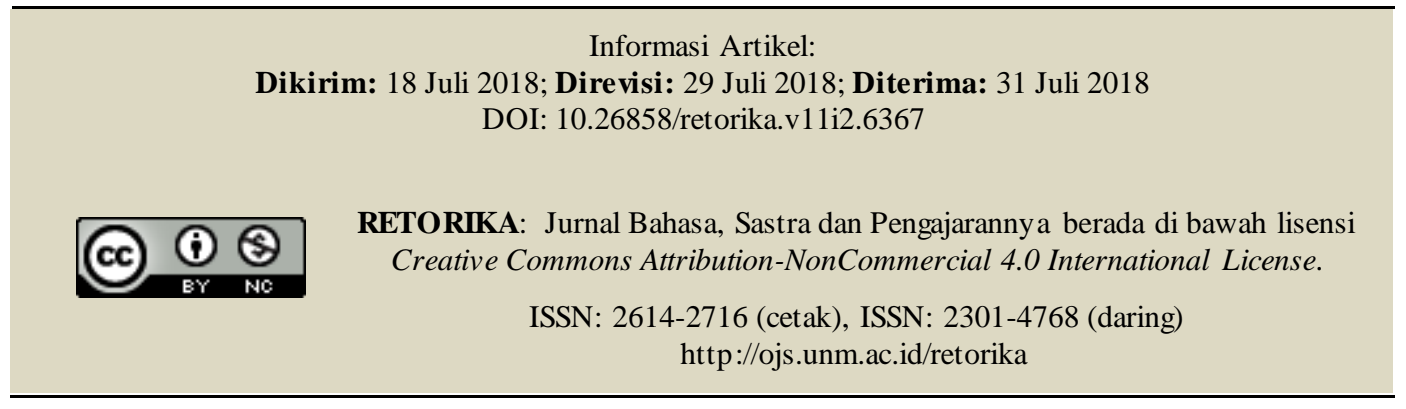

\begin{abstract}
Code-Mixing Javanese Language of Banyumasan in Indonesian Language Learning at Vocational High School. This research will describe: (1) the form of code mixing, and (2) the factor that causing of code mixing that occur in the process of Indonesian learning class. Data and data sources in this research are a written data about speech that appear in a process of Indonesian language learning. Validity data technique is use triangulation of data source and informant review. Data analysis used intralingual method. The results of this study found the use of code mixing in Indonesian learning class in The Public Vocational High School of Banyumas. The form of code mixing that found are namely: (1) word insertion, (2) phrase insertion, (3) clause insertion, (4) the word repetition, and (5) idiom. The factor that causing of code mixing are: (1) changing situation, (2) want to explain something, and (3) establishing intimacy between teacher and student.
\end{abstract}

\begin{abstract}
Abstrak: Campur Kode Bahasa Jawa Banyumasan dalam Pembelajaran Bahasa Indonesia di Sekolah Menengah Kejuruan. Penelitian ini bertujuan mendeskripsikan dan menjelaskan (1) wujud dan (2) faktor penyebab terjadinya campur kode dalam proses pembelajaran Bahasa Indonesia. Data penelitian berupa campur kode guru dan siswa yang muncul pada pembelajaran Bahasa Indonesia di SMK Negeri 1 Banyumas. Pengumpulan data menggunakan metode simak dan cakap. Validitasi data menggunakan teknik triangulasi sumber data dan review informan. Analisis data dengan menggunakan metode padan intralingual. Hasil dari penelitian menunjukkan bahwa wujud campur kode berupa (1) penyisipan kata, (2) penyisipan frase, (3) penyisipan klausa, (4) penyisipan pengulangan kata, dan (5) penyisipan ungkapan. Faktor penyebab terjadinya campur kode, yaitu: (1) berubahnya situasi, (2) ingin menjelaskan sesuatu, dan (3) menjalin keakraban antara guru dan siswa.
\end{abstract}

Kata Kunci: pemakaian bahasa, campur kode, pembelajaran bahasa Indonesia, dan Banyumas 
Pemilihan bahasa di lingkungan pendidikan menjadi perhatian karena seorang guru harus mengerti cara menyampaikan pembelajaran kepada siswa yang semakin multilingual. Penelitian Wang dan Kirkpatrick (2012) menyatakan guru Bahasa Cina berusaha mematuhi satu-satunya prinsip menggunakan Bahasa Cina, namun Bahasa Inggris secara teratur dan strategis sudah menjadi bahasa internasional yang berfungsi untuk menjelaskan, memanajerial, dan berinteraksi. Disimpulkan bahwa dalam pembelajaran, guru bahasa Cina perlu mempertimbangkan penggunaan bahasa Inggris di kelas yang semakin multilingual. Hal tersebut menunjukan bahwa pemilihan bahasa di kelas perlu diperhatikan karena siswa yang semakin multilingual.

Krishnasamy (2015:788-792) membahas perilaku berbahasa pada anak yang hidup dalam keluarga bilingual. Hasil kajiannnya menunjukkan bahwa anak bilingual lebih banyak menggunakan campur kode dalam kesehariannya dengan tetap memertahankan bahasa budayanya. Sekaitan dengan hasil penelitian Krishnasamy, pada penelitian ini guru dan siswa dalam kehidupan sehari-hari dominan menggunakan bahasa Jawa Banyumasan. Hal tersebut berdampak pada munculnya campur kode dalam pembelajaran bahasa Indonesia.

Penelitian mengenai campur kode banyak ditemukan pada proses pembelajaran, seperti temuan Hossain dan Bar (2015) di Bangladesh, Krishnasamy (2015) di India, Ariffin dan Husin (2011) di Malaysia, serta Ayemoni (2006) di India. Hasil penelitian tersebut mengungkap bahwa penggunaan campur kode dalam proses pembelajaran disebabkan oleh pengaruh budaya dan masyarakat yang bilingual. Temuan tersebut memberikan penekanan bahwa penggunaan bahasa dalam proses pembelajaran perlu diperhatikan agar tidak berpengaruh buruk pada keterampilan berbahasa siswa.

Dalam proses pembelajaran, terjadi perubahan-perubahan variasi kebahasaan dan penggunaan dari satu kode bahasa ke kode bahasa yang lain. Perubahan tersebut terjadi karena guru dan siswa memiliki latar belakang atau faktor sosial yang berbeda yang mengakibatkan perbedaan referensi dan penguasaan bahasa tiap individu. Kurangnya penguasaan bahasa yang dimiliki menyebabkan terjadinya penggunaan lebih dari satu bahasa yang berdampak pada munculnya fenomena campur kode dalam proses belajar mengajar di kelas.
Penggunaan campur kode dalam proses pembelajaran bahasa Indonesia sulit untuk dihindari. Beberapa penelitian menemukan penggunaan campur kode dalam proses pembelajaran bahasa Indonesia. Hasil penelitian Saddhono dan Rohmadi (2014) menemukan bahwa terda-pat penggunaan bahasa ibu, alih kode, dan cam-pur kode dalam proses pembelajaran tingkat Se-kolah Dasar di Surakarta. Penelitian Susmita (2015) menemukan penggunaan alih kode dan campur kode dalam proses pembelajaran bahasa Indonesia tingkat Sekolah Menengah Pertama di Kerinci. Hasil penelitian Rulyandi, Rohmadi, dan Sulistyo (2014) menemukan adanya peng-gunaan alih kode dalam proses pembelajaran ba-hasa Indonesia tingkat Sekolah Menengah Atas di Yogyakarta. Penelitian Sari dan Wedasuwari (2014) pada saat proses pembelajaran tingkat sekolah menengah atas di Bali juga menemukan penggunaan alih kode dan campur kode.

Beberapa penelitian di atas menunjukan adanya penggunaan campur kode pada semua tingkatan pendidikan, dari sekolah dasar hingga tingkat menengah atas. Sebagian besar siswa di Indonesia merupakan dwibahasawan karena Indonesia adalah negara yang kaya akan bahasa daerah dan memiliki bahasa Indonesia sebagai bahasa nasional. Suwandi (2008:1) mengemukakan perlunya memfokuskan pada cara mengefektifkan pengajaran bahasa Indonesia dengan memerhatikan sebagian besar pelajar yang dwibahasawan. Hal tersebut merupakan tantangan yang besar bagi guru agar memiliki metode dan strategi mengajar yang tepat untuk menghadapi siswa yang dwibahasawan.

Faktor pendorong terjadinya campur kode dijabarkan oleh Indra (2008:36), yaitu ekstralinguistik dan intralinguistik. Faktor ekstralinguistik dipengaruhi oleh hal-hal di luar kebahasaan seperti, terkait dengan tujuan pembicaraan, situasi pembicaraan, tingkat pendidikan, status sosial, lawan bicara, dan sifat pembicaraan. Faktor ekstralingustik bisa juga muncul dari keinginan penutur untuk menjelaskan, menyatakan prestise, melucu, menggunakan bahasa yang bermakna kias, dan sebab-sebab lainnya. Faktor intralingustik berkaitan dengan hal-hal yang ada dalam bahasa itu sendiri, seperti tidak ada leksikon dari bahasa asli untuk konsep-konsep tertentu, leksikon bahasa asli belum atau tidak mewahanai kosep yang dimaksud dalam bahasa lain, dan sebab-sebab lainnya. 
Fenomena campur kode yang terjadi apabila seorang penutur menggunakan suatu bahasa secara dominan, mendukung suatu tuturan disisipi dengan unsur bahasa lainnya. Kridalaksana (2011) berpendapat bahwa campur kode merupakan penggunaan bahasa satu ke bahasa lain dengan tujuan untuk memperluas gaya atau ragam bahasa, termasuk kata, klausa, idiom dan sebagainya. Pendapat lainnya dikemukakan oleh Saddhono (2012:75) yang mengatakan bahwa campur kode adalah penggunaan dua bahasa atau lebih dengan menyisipkan unsur-unsur ba-hasa lain.

Menurut Suwandi (2008:88) yang mencirikan campur kode, yaitu: (1) penggunaan dua bahasa atau lebih untuk itu berlangsung dalam situasi informal, santai, dan akrab; (2) tidak ada sesuatu dalam situasi berbahasa itu yang menuntut terjadinya campur kode; dan (3) campur ko-de dapat berupa pemakaian kata, klausa, idiom, sapaan, dan sebagainya. Dapat diketahui bahwa ciri yang menonjol dari campur kode adalah kesantaian atau situasi informal.

Berdasarkan pendapat para ahli disimpulkan bahwa campur kode dalam penelitian ini adalah peristiwa atau suatu keadaan menggunakan satu bahasa atau lebih dengan memasukan unsur bahasa lain secara bersamaan yang dilakukan dalam keadaan santai dan tanpa ada sesuatu yang menuntut percampuran bahasa itu. Jenisjenis campur kode dijabarkan Indra (2008) berdasarkan hubungan kekerabatan antarbahasa sumber dan bahasa sasaran, yaitu campur kode ke luar (outer code-mixing), ke dalam (inner codemixing), dan campuran (hybrid code mixing). Sejalan dengan pendapat itu, Azhar (2011:17) membagi campur kode menjadi dua, yaitu: (1) campur kode ke dalam (inner code-mixing), yaitu campur kode yang berasal dari bahasa asli dengan segala variasinya; dan (2) campur kode ke luar (outer code-mixing), yaitu campur kode yang berasal dari bahasa asing.

Jenis campur kode juga dijabarkan oleh Muysken (2000:3) berdasarkan unsur kebahasaan dalam campur kode, yaitu: (1) penyisipan materi, leksikal, atau keseluruhan unsur pokok dari satu bahasa ke struktur bahasa lain; (2) pergantian antara struktur bahasa dan kongmen leksikal dari leksikal yang berbeda ke dalam gramatikal yang sama.

Menurut Suwito (dalam Maemunah 2013: 45) ada beberapa wujud campur kode yaitu: (1) penyisipan kata; (2) penyisipan frasa; (3) penyi- sipan klausa; (4) penyisipan ungkapan atau idiom; dan (5) penyisipan bentuk baster (gabungan pembentuk asli dan asing). Suwito (dalam Hestiyana 2013:40) mengemukakan bahwa di dalam campur kode terdapat ciri-ciri ketergantungan dalam campur kode yaitu hubungan timbal balik antar peranan (penutur) dan fungsi kebahasaan (tujuan ungkapan dari penutur).

Penelitian mengenai campur kode di Banyumas pernah dilakukan oleh Devi (2013) dengan meneliti macam-macam dan faktor penyebab alih kode dan campur kode di Kalibagor. Dalam penelitian Rosita dilakukan pada kegiatan belajar mengajar di sekolah tersebut. Berbeda dengan penelitian tersebut, kajian ini lebih fokus pada penggunaan campur kode dalam proses pembelajaran bahasa Indonesia dengan situasi dan kondisi yang berbeda.

SMK Negeri 1 Banyumas merupakan sekolah yang berada di pinggiran kota yang masih kental dengan budaya. Guru dan siswa sering menggunakan bahasa Jawa Banyumasan dan bahasa Indonesia dalam kesehariannya pada saat di lingkungan sekolah. Baik siswa dan guru yang dwibahasawan memunculkan fenomena campur kode. Berdasarkan penggunaan dua bahasa tersebut perlu diketahui apakah guru dan siswa menggunakan campur kode dalam proses pembelajaran.

Penelitian mengenai campur kode akan membantu guru dalam mempersiapkan materi pelajaran, metode pembelajaran, dan evaluasi pembelajaran dengan memperhatikan situasi dan kondisi siswa yang dwibahasawan. Selain itu penelitian tentang bahasa dapat menambah wawasan dan menjadi dasar pertimbangan guru dalam membuat strategi pembelajaran dengan memperhatikan situasi dan kondisi siswa yang dwibahasawan.

Masyarakat Indonesia juga merupakan masyarakat yang memiliki lebih dari satu bahasa. Penelitian Damayanti (2016) pada anak tingkat Sekolah Dasar menemukan bahwa anak-anak saat ini sudah menggunakan lebih dari satu bahasa, yaitu bahasa Ibu dan bahasa Nasional. Hal itu menunjukan bahwa banyak masyarakat yang menguasai lebih dari satu bahasa/bilingual.

Berdasarkan latar belakang tersebut, penelitian didesain untuk menganalisis penggunaan campur kode yang terjadi dalam pembelajaran Bahasa Indonesia di SMK Negeri 1 Banyumas. Penelitian ini bertujuan mengkaji bentuk campur kode yang terjadi dalam proses pembel- 
ajaran Bahasa Indonesia dan (2) faktor-faktor yang menyebabkan terjadinya campur kode.

\section{METODE}

Penelitian ini merupakan penelitian kualitatif dengan metode deskriptif. Penelitian ini mendeskripsikan peristiwa campur kode dan penyebab campur kode dalam proses pembelajaran di SMK Negeri 1 Banyumas. Data penelitian berupa campur kode yang muncul dalam interaksi antara guru dan siswa pada pembelajaran Bahasa Indonesia di SMK Negeri 1 Banyumas. Sumber data dalam penelitian ini adalah peristiwa tutur guru dan siswa SMK Negeri 1 Banyumas.

Pengumpulan data penelitian ini menggunakan metode simak dan cakap. Teknik simak libat cakap disertai dengan penerapan teknik rekam dan catat. Pengamatan dilakukan pada saat proses belajar mengajar berlangsung. Pengamatan difokuskan pada bentuk campur kode dan faktor penyebabnya. Observasi dilakukan berdasar pada pedoman observasi yang telah dibuat, yaitu sesuai dengan penyajian data melalui perekaman dan pencatatan. Alat yang digunakan, yaitu alat perekam suara dan gambar. Selama proses pembelajaran, peneliti tidak terlibat dalam percakapan.

Analis data dilakukan dengan mengelompokkan data berdasarkan kesamaan karakteristik objek yang dikaji, yaitu alih kode. Selanjutnya, dilakukan analisis data dengan menggunakan metode padan intralingual. Metode padan intralingual menurut Mahsun (2012:259-260) merupakan metode analisis dengan cara menghubung-bandingkan unsur-unsur yang bersifat lingual, baik yang terdapat dalam satu bahasa maupun dalam beberapa bahasa yang berbeda. Teknik yang digunakan untuk menguji validitas data adalah teknik triangulasi sumber dan review informan. Menurut Mahsun (2012:270) dalam analisis kualitatif terdiri dari empat komponen, yaitu: (1) tahap penyediaan data; (2) reduksi data; (3) penyajian data; dan (4) pengambilan kesimpulan. Hasil simpulan diperoleh berdasarkan temuan-temuan selama proses penelitian berlangsung dan dalam tahap penulisan.

Dalam menyajikan data, digunakan singkatan sebagai berikut.

G: guru

S1: siswa 1

S2: siswa 2

\section{HASIL DAN PEMBAHASAN}

\section{Hasil}

Berdasarkan hasil penelitian, ditemukan wujud dan faktor-faktor penggunaan campur kode dalam interaksi antara guru dan siswa. Berikut paparan hasil penelitian.

\section{Wujud Campur Kode}

Hasil penelitian yang dikemukakan merupakan peristiwa tutur yang dilakukan oleh guru dan siswa yang yang menggunakan campur kode dalam proses pembelajaran Bahasa Indonesia di SMK Negeri 1 Banyumas. Campur kode yang ditemukan, yaitu penyisipan kata, penyisipan frasa, campur kode berupa klausa, campur kode berupa idiom atau ungkapan dan campur kode berupa pengulangan kata.

\section{Campur Kode Berupa Penyisipan Kata}

Berikut merupakan peristiwa tutur yang menggunakan campur kode ke dalam berupa penyisipan kata pada proses pembelajaran Bahasa Indonesia SMK Negeri 1 Banyumas.

Data (1)

G: Sudah ditandatanganiorang tua belum? (1)

S1: Pak gawat pak, sudah tak sobek. (2)

S2: Teles pak, kalo sore hujan terus. (3)

(Basah Pak, kalau sore hujan terus)

Situasi Tutur : Kelas X AKL 1

Tujuan Tutur : Memberikan alasan

Topik Tutur : Pengumpulan surat nilai UTS

Tuturan (2) pada data (1), menunjukkan siswa menyisipkan kata bahasa Jawa Banyumasan ke dalam kalimat bahasa Indonesia, seperti kata "tak" yang artinya 'saya atau aku'. Kemudian pada tuturan (3), siswa menggunakan campur kode berupa penyisipan kata, yaitu "teles" yang artinya 'basah'. Kata tersebut digunakan oleh siswa ketika memberikan alasan tertundanya pengumpulan nilai yang sudah ditandatangani oleh orang tua. Peristiwa campur kode tersebut merupakan campur kode ke dalam berupa penyisipan kata.

\section{Campur Kode Berupa Frasa}

Data (2) berikut merupakan peristiwa tutur yang menggunakan campur kode ke dalam 
yaitu bahasa Indonesia ke dalam bahasa Jawa Banyumasan berupa penyisipan frasa.

Data (2)

G: Sana Sela sama Gisel, ambil buku dua menit. (4)

S: Dua menit sampe turun tangga balik maning. (5)

(Dua menit sampai turun tangga balik lagi)

Situasi tutur: Kelas X AKL 1

Tujuan tutur: Untuk menanggapi perintah guru

Topik tutur: Menanggapi perintah guru

Dalam peristiwa tutur pada data (2), terdapat campur kode bahasa Indonesia ke dalam bahasa Jawa Banyumasan berupa frasa keterangan pada kutipan "balik maning" yang artinya 'balik lagi'. Situasi saat itu seorang siswa merespon perintah guru yang tidak memungkinkan. Campur kode tersebut digunakan untuk mengubah suasana agar lebih santai dan akrab, serta tidak membosankan. Peristiwa campur kode tersebut merupakan peristiwa campur kode ke dalam, yaitu bahasa Indonesia ke bahasa Jawa Banyumasan berupa frasa

\section{Campur Kode Berupa Klausa}

Data (3) berikut merupakan peristiwa tutur yang menggunakan campur kode ke dalam berupa klausa, yaitu bahasa Indonesia ke dalam bahasa Jawa Banyumasan.

Data (3)

G: Di instagramnya kan kayané kemarin lagi sakit (6)

(Di instagramnya kan sepertinya kemarin sedang sakit)

S1: Nyong malah ora ndué Instagram, bukan anak gaul (7)

(Saya malah tidak punya Instagram, bukan anak gaul)

S2: Putri kuwé Pak (8)

(Itu Putri)

Situasi tutur: Kelas XI TKJ 3

Tujuan tutur: Untuk mengecek kehadiran siswa Topik tutur: Presensi siswa

Pada tuturan (6) guru menggunakan dua bahasa, yaitu bahasa Indonesia ke dalam bahasa Jawa Banyumasan. Siswa menggunakan campur kode berupa klausa pada tuturan (7), yaitu "Nyong malah ora ndué Instagram, bukan anak gaul" yang artinya 'Saya malah tidak punya Instagram, bukan anak gaul'. Campur kode tersebut digunakan untuk membuat suasana menja- di lebih santai dan tidak membosankan. Peristiwa campur kode tersebut merupakan peristiwa campur kode ke dalam, yaitu bahasa Indonesia ke bahasa Jawa Banyumasan berupa klausa.

\section{Campur Kode Berupa Idiom atau Ungkapan}

Berikut merupakan peristiwa tutur yang menggunakan campur kode ke dalam berupa idiom atau ungkapan dalam bahasa Indonesia.

Data (4)

G: Contohnya gini, raja siang. Apa kuwe raja siang? (9)

S: Matahari (10)

G: Bintang kelas? (11)

S: Juara kelas. (12)

G: Buah bibir, apa? (13)

S1: Sariawan, Pak. (14)

S2: Jadi bahan perbincangan, Pak. (15)

S3: Buah hati. (16) (Anak kandung)

Situasi tutur: Kelas X TKP 1

Tujuan tutur: Memberikan contoh majas

Topik tutur: Contoh majas antonomasia

Pada peristiwa tutur (data 4) tersebut terdapat beberapa ungkapan, seperti pada tuturan (9) yaitu raja siang yang artinya 'matahari', tuturan (11) yaitu bintang kelas yang artinya 'juara kelas', tuturan (13) yaitu buah bibir yang artinya 'bahan perbincangan', dan tuturan (16) yaitu buah hati yang artinya 'anak kandung'. Ungkapan tersebut digunakan sebagai contoh dari majas. Peristiwa campur kode tersebut merupakan capur kode ke dalam yaitu ungkapan dalam bahasa Indonesia.

Data (5)

G: Ya mungkin kan ada yang seperti itu, wong saya dengernya itu dari luar seperti itu berarti kan ada yang tidak. (17)

S: Tapi ya tergantung orange sih Pak. (18)

G: Nah tergantung orang masing-masing individu, nah nilai moral ini juga bisa dipengaruhi dari bagaimana kalian berinteraksi di rumah dan di lingkungan sekitar. Harus mikul dhuwurmendem jero, yambok? (19)

(Nah, tergantung orang masing-masing indivi$\mathrm{du}$, nah nilai moral ini juga bisa dipengaruhi dari bagaimana kalian berinteraksi di rumah dan di lingkungan sekitar. Harus memikul tinggi menanam dalam/bertanggung jawab dengan menjaga nama baik sekolah).

Situasi Tutur: Kelas X TKP 2 
Tujuan Tutur: Memberi contoh nilai pada hikayat Topik tutur: Nilai kehidupan dalam hikayat

Pada peristiwa tutur (data 5) tersebut terdapat campur kode pada tuturan (19), yaitu mikul dhuwur mendemjero yang dalam bahasa Indonesia memiliki makna 'memikul tinggi, menanam dalam' artinya harus selalu bertanggung jawab dengan menjaga nama baik orang tua atau dalam kasus ini menjaga nama baik sekolah. Ungkapan tersebut digunakan guru untuk memberi penjelasan mengenai contoh nilai dalam hikayat. Peristiwa campur kode tersebut merupakan campur kode ke dalam, yaitu penggunaan ungkapan dalam bahasa Jawa Banyumasan.

\section{Campur Kode berupa Pengulangan Kata}

Berikut merupakan peristiwa tutur yang menggunakan campur kode ke dalam berupa pengulangan kata.

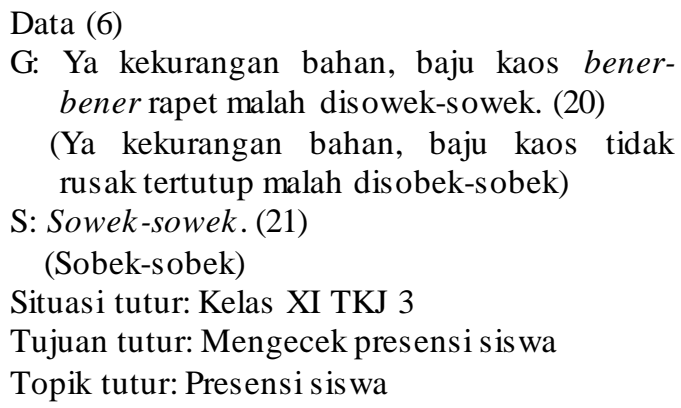

Pada peristiwa tutur (data 6) terdapat campur kode pada tuturan (20), yaitu bener-bener yang artinya 'tidak rusak atau benar' dan soweksowek yang artinya 'sobek-sobek'. Penggunaan campur kode bertujuan untuk memberikan contoh dari materi namun dengan suasana yang menyenangkan sehingga menarik minat siswa untuk menanggapi secara aktif. Peristiwa tutur di atas merupakan campur kode ke dalam, yaitu penggunaan bahasa bahasa Jawa Banyumasan ke dalam bahasa Indonesia berupa kata ulang.

Berdasarkan data yang telah dipaparkan, dapat disimpulkan bahwa campur kode yang terjadi dalam dalam pembelajaran Bahasa Indonesia di kelas X dan XI SMK Negeri 1 Banyumas, yaitu: (1) campur kode penyisipan kata, (2) campur kode penyisipan frase, (3) campur kode penyisipan klausa, (4) campur kode penyisipan pengulangan kata, dan (5) campur kode penyisipan ungkapan atau idiom.

\section{Faktor Penyebab Penggunaan Campur Kode}

Penggunaan campur kode dalam pembelajaran bahasa Indonesia di SMK Negeri $1 \mathrm{Ba}-$ nyumas disebabkan oleh beberapa faktor. Faktor penyebab terjadinya campur kode yang ditemukan dalam penelitian ini yaitu: (1) berubahnya situasi, (2) penjelasan sesuatu, dan (3) menunjukkan keakraban.

\section{Berubahnya Situasi}

Dalam situasi pembelajaran bahasa Indonesia, interaksi antara guru dan siswa terlihat serius dan santai. Guru menggunakan campur kode untuk membuat siswa lebih santai dalam berkomunikasi agar siswa berani untuk mengungkapkan pendapatnya di depan kelas. Pada saat pembelajaran bahasa Indonesia, siswa lebih banyak menanggapi atau merespon guru ketika situasi pembelajaran lebih santai, oleh karena itu guru sering menggunakan campur kode agar siswa lebih aktif berinteraksi.

Data (7)

G: Ya, ditandai dengan rumah yang berpagar tinggi, lalu ditutupi pula dengan fiber-glass. Di lingkungan kalian masih ada yang seperti itu? (22)

S: Ada (23)

G: Ada ya, apalagi kalau lingkungan perumahan. Perumahan ada, apalagi rumah jéjéran itu jadi bisa gak kenal. Itu kalau di perumahan, kalau di tempat kalian? (24) (Ada ya, apalagi kalau lingkungan perumahan. Perumahan ada, apalagi rumah bersebelahan itu jadi bisa tidak kenal. Itu kalau di perumahan, kalau di tempat kalian?)

$\mathrm{S}$ : Kenal ra kenal, ya dewek-dewek, sudah biasa Pak. (25)

G: Sama saja. Ora kenal, lha ngapa sih? (26)

S1: Astagfirullah Al Adzim, (aku mohon ampun kepada Allah yang Maha Agung) ora kenal ya kenalan! (27)

S2: Astagfirullah, haha (28)

G: Baliné soré ya, arép kénalan wis késél. Angger setu minggu jatahé dolan ya? Ora mungkin nugas ya?.Tugas dilupakan. (29) (Pulangnya sore, mau kenalan sudah capek. Kalau sabtu minggu jatahnya main ya? Tidak mungkin mengerjakan tugas ya? Tugas dilupakan)

S: Iya lah pak. (30)

G: Oiya jadi inget, kelas ini yang belum mengumpulkan tugas siapa? (31)

S: Nur... (32) 
Situasi tutur: Kelas XI TKJ 3

Tujuan tutur: Memberi contoh

Topik tutur: Menjelaskan materi cerpen

Peristiwa tutur (data 7), awalnya guru memberikan penjelasan dengan bahasa Indonesia, kemudian guru mencampur ke dalam bahasa Jawa Banyumasan pada saat guru hendak berinteraksi dengan siswa. Situasi awal pada saat guru menjelaskan materi adalah serius dan siswa banyak diam menyimak materi yang disampaikan. Kemudian saat guru memberikan sebuah pertanyaan, guru menggunakan bahasa Jawa Banyumasan, agar siswa lebih santai dan tidak takut dalam menanggapi atau merespon pertanyaan guru. Terlihat pada tuturan di atas, siswa lebih aktif dalam berinteraksi dan tidak hanya satu siswa saja. Peristiwa di atas merupakan peristiwa campur kode dari bahasa Indonesia ke dalam bahasa Jawa Banyumasan dalam proses pembelajaran Bahasa Indonesia yang disebabkan oleh faktor berubahnya situasi.

\section{Penjelasan Sesuatu}

Penggunaan campur kode juga disebabkan karena terbatasnya kosakata yang dimiliki oleh siswa sehingga guru menggunakan campur kode untuk mempermudah siswa dalam memahami materi yang sulit dijelaskan dalam bahasa Indonesia. Terbatasnya kosakata siswa dikarenakan siswa terbiasa menggunakan ba-hasa Jawa Banyumasan dalam kesehariannya. Penggunaan campur kode juga untuk menjelaskan materi yang sulit dideskripsikan dalam bahasa Indonesia. Namun penggunaan campur kode juga tetap dalam pengawasan guru, agar siswa tidak seenaknya sendiri dan tidak fokus pada materi.

Pada saat membahas mengenai budaya Banyumasan, guru lebih mudah menjelaskan menggunakan bahasa Jawa Banyumasan yang mudah dipahami oleh siswa. Guru menggu-nakan bahasa Jawa Banyumasan yang mudah dimengerti oleh siswa untuk mengganti kata-kata yang sulit diungkapkan menggunakan bahasa Indonesia. Hal itu menunjukkan penggunaan alih kode yang memudahkan pemahaman siswa.

Data (8)

G: Lha karena percaya, lah yang namanya percaya ya, biasanè ya tèmènan, kèdadian. (33)
(Ada lagi istilah, masih dari kebudayaan yang ada di Banyumas, misalnya kalau perawan $g a$ boleh duduk di depan pintu).

S: Prawan tua. (34)

G: Nilai-nilai seperti itu kan sebenarnya,agar tidak menghalangi jalan. Karena yang namanya duduk di depan pintu itu janè enak. (35)

S: Iya bener. (36)

S1 : Anu silir nèng ngarèp lawang. (37)

G: Silir, masuknya angin, terus pas tanahnya kan adem. Karena orang zaman dulu kalau rumah joglo, apalagi kalau rumahnya itu tanahnya tanah wingit.(38)

S1: Apa? (39)

S2: Wingit si apa? (40)

G: Apa ya? Misal yang tanah yang ditakuti sama warga itu apa? (41)

S: Angker. (42)

G: Nah iya tanah angker. (43)

S: Lhaaah angèl tèmèn arèp ngomong angkèr . (44)

G: Nah kalau orang zaman dahulu seperti itu, tanahnya wingit terus mbangun rumah, supaya setannyanggak masuk ke rumah di depan pintu itu tiduran. (45)

S: Apa iya? (46)

G: Iya coba setiap hari selama seminggu. (47)

S: Setahun pak? (48)

G: Sètahun awakè ya rèmèk itu katanya, kalau sekarang saya tidak tahu masih ada atau tidak. ... Kelompoknya masih tetap sama dengan kelompok yang dulu. (49)

Situasi tutur : Kelas X AKL 1

Tujuan tutur: Menyampaikan materi

Topik tutur: Menjelaskan materi nilai budaya

Peristiwa tutur pada data (8) tersebut, menujunjukkan guru menggunakan bahasa Indonesia menjelaskan suatu materi nilai budaya, materi yang diambil contoh adalah budaya Banyumasan. Guru menggunakan bahasa Jawa Banyumasan, karena istilah-istilah yang digunakan adalah istilah budaya Banyumasan misalnya pada tuturan (180) yaitu 'wingit' yang artinya 'angker', 'remek' yang artinya 'hancur', dan 'kedadèan' yang artinya 'kejadian'. Kemudian siswa juga menggunakan beberapa istilah dalam bahasa Banyumasan seperti 'silir' yang artinya 'segar atau sejuk atau semilir' dan kata 'lawang' yang artinya 'pintu'. Peristiwa di atas merupakan peristiwa campur kode dari bahasa Indonesia ke dalam bahasa Jawa Banyumasan dalam proses pembelajaran Bahasa Indonesia yang disebabkan oleh faktor hendak menjelaskan sesuatu. 


\section{Keakraban}

Penggunaan campur kode juga dikarenakan faktor untuk menjalin keakraban baik antara guru dan siswa, maupun antara siswa dan siswa. Penutur menggunakan campur kode dengan bentuk dan variasi bahasa yang lain untuk menjalin sikap keakraban agar siswa tidak merasa jenuh atau bosan dan takut pada guru dalam proses pembelajaran bahasa Indonesia. Namun demikian, guru tetap membatasi jarak dengan siswa, agar siswa tetap menanamkan sikap hormat pada guru.

Data (9)

G: Ya dengarkan aja reang bae (50)

(Ya dengarkan jangan ribut terus)

Si: Aja reang (51)

(Jangan rebut)

Situasi tutur: Kelas XI TKJ 3

Tujuan tutur: Konfirmasi kejelasan materi

Topik tutur: Menjelaskan materi cerpen

Data (9) merupakan peristiwa campur kode bahasa Indonesia dengan bahasa Jawa Banyumasan yang terjadi dalam proses pembelajaran Bahasa Indonesia di SMK Negeri $1 \mathrm{Ba}-$ nyumas. Awalnya guru menggunakan bahasa Indonesia, kemudian guru melakukan campur kode dengan bahasa Jawa Banyumasan, yaitu 'aja reang bae', yang artinya 'jangan ribut terus'. Guru menegur siswa namun menggunakan campur kode agar siswa mau menuruti guru namun tidak dengan rasa takut. Campur kode tersebut memberi kesan keakraban antara guru dan siswa. Campur kode tersebut digunakan untuk mengubah suasana pembelajaran menjadi tertib dan santai, agar siswa tidak merasa jenuh atau bosan pada saat proses pembelajaran. Peristiwa tersebut merupakan peristiwa campur kode dari bahasa Indonesia ke dalam bahasa Jawa $\mathrm{Ba}$ nyumasan dalam proses pembelajaran Bahasa Indonesia yang disebabkan oleh faktor untuk menjalin keakraban.

Berdasarkan data yang telah dipaparkan, disimpulkan bahwa pada proses pembelajaran bahasa Indonesia penggunaan campur kode disebabkan faktor (1) berubahnya situasi, (2) untuk menjelaskan sesuatu, dan (3) untuk menjalin sikap keakraban antara guru dan siswa.

\section{Pembahasan}

Setelah dilakukan penelitian diketahui bahwa pada saat pembelajaran bahasa Indonesia baik guru dan siswa sering menggunakan dua bahasa, yaitu bahasa Indonesia dan bahasa Jawa Banyumasan. Berdasarkan arahnya, campur kode yang muncul dalam pembelajaran Bahasa Indonesia di SMK Negeri 1 Banyumas, yaitu campur kode ke luar (outer code-mixing), ke dalam (inner code-mixing), dan campuran (hybrid code mixing).

Tabel 1. Campur Kode Berdasarkan Jenisnya

\begin{tabular}{ccc}
\hline No & Jenis Campur Kode & Frekuensi \\
\hline 1. & Campur kode ke dalam & 64 \\
\hline 2. & Campur kode keluar & 17 \\
\hline 3. & Campuran & 7 \\
\hline & Jumlah & 88 \\
\hline
\end{tabular}

Berdasarkan Tabel 1 dapat diketahui bahwa jenis campur kode yang dominan adalah campur kode ke dalam (inner code-mixing), yaitu sebanyak 64 tuturan, sedangkan campur kode yang jarang digunakan adalah campur kode campuran (hybrid code mixing), yaitu sebanyak 7 tuturan. Campur kode ke dalam, yaitu dari bahasa Indonesia ke dalam bahasa Jawa Banyumasan, dan dari bahasa Jawa Banyumasan ke dalam bahasa Indonesia.

Berdasarkan pemaparan data diketahui bahwa penggunaan bahasa dalam proses pembelajaran Bahasa Indonesia di SMK Negeri 1 Banyumas dominan dipengaruhi oleh bahasa daerah. Hasil yang sama diperoleh oleh Nurlaila (2016) bahwa bahasa daerah sangat berpengaruh dalam bahasa yang digunakan oleh anak-anak. Hal tersebut disebabkan oleh faktor lingkungan keluarga dan lingkungan tempat anak-anak itu bermain.

Dalam penelitian ini menemukan 5 wujud campur kode yaitu penyisipan kata, frasa, klausa, ungkapan atau idiom, dan pengulangan kata. Berbeda dengan hasil penelitian Herawati (2016) yang hanya menemukan wujud campur kode berupa kata, frasa, dan klausa. Faktor penyebab terjadinya campur kode yaitu persamaan latar belakang bahasa dan budaya, dan faktor lingkungan. Perbedaan hasil dan objek penelitian dipengaruhi oleh kondisi dan waktu pada saat dilakukannya penelitian.

Munculnya campur kode dalam sebuah peristiwa tutur selalu memiliki faktor penyebab tertentu. Seperti yang sudah dikemukakan sebelumnya bahwa dalam penelitian ini menemukan 
tiga faktor penyebab, yaitu berubahnya situasi, penjelasan sesuatu dan keakraban. Penelitian Nirmala (2013) menemukan empat faktor penyebab terjadinya alih kode dan campur kode, yaitu: (1) menciptakan suasana humor, (2) menciptakan suasana santai, (3) menciptakan suasana akrab, dan (4) penekanan suatu topik pembicaraan pada mitra tutur.

Penggunaan campur kode dalam pembelajaran Bahasa Indonesia di SMK Negeri $1 \mathrm{Ba}-$ nyumas disebabkan karena penutur dan mitra tuturnya merupakan masyarakat suku Jawa de-ngan dialek Banyumasan sehingga penutur menysuaikan mitra tutur. Wardaugh (2006) mengemukakan bahwa ketika seseorang berbicara, dia harus secara konstan melakukan beberapa pertimbangan, seperti dengan siapa dia berbicara, bagaimana menyampaikannya, kalimat-kalimat, kata-kata dan intonasi yang seperti apa yang harus dilakukan dan sebagainya.

Perkembangan zaman mendorong seseorang untuk menggunakan alih kode dan campur kode. Hasil penelitian Sumarsih, Siregar, Bahri, dan Sanjaya (2014 menunjukkan bahwa seseorang menggunakan alih kode dan campur kode karena tidak memerhatikan situasi dan menyisipkan kata-kata ke dalam bahasa pertamanya. Selain itu, seseorang menggunakannya agar terlihat keren dan mengikuti perkembangan zaman.

Faktor penyebab penggunaan campur kode paling banyak ditemukan adalah faktor keakraban sejumlah 51 data, berubahnya situasi 36 data, dan penjelasan sesuatu sebanyak 33 data. Hal tersebut menunjukan bahwa antara siswa dan guru memiliki hubungan keakraban yang baik. Penggunaan campur kode terjadi karena siswa dan guru menggunakan bahasa daerah sebagai bahasa keseharian sehingga budayanya masih terasa kuat.

Penggunaan campur kode dalam proses pembelajaran bahasa Indonesia dapat memberikan dampak yang berarti pada keterampilan berbahasa siswa. Penelitian Ariffin dan Husin (2011) dalam pembelajaran bahasa Inggris di Malaysia menemukan bahwa alih kode dan campur kode dapat membantu siswa dalam memahami materi namun perilaku, seperti itu dapat dianggap menyimpang karena tidak membantu meningkatkan kompetensi linguistik. Penelitian yang dilakukan Rulyandi, Rohmadi, dan Sulistyo (2014) dalam pembelajaran bahasa Indonesia di Yogyakarta mengungkap bahwa terjadinya campur kode memberi dampak negatif, yaitu rusaknya tatanan bahasa Indonesia yang diakibatkan dari terjadinya interferensi dan integrasi, serta terjadinya alih kode dan campur kode penggunaan bahasa Indonesia tidak dilakukan secara baik dan benar sehingga dalam pembelajaran situasi menjadi tidak formal. Dengan demikian, dampak-dampak negatif tersebut hendaknya menjadi catatan bagi guru dalam menggunakan campur kode pada pembelajaran bahasa Indonesia.

Penggunaan campur kode dalam proses pembelajaran bahasa Indonesia memberi gambaran bahwa pembelajaran dapat berjalan efektif meskipun menggunakan campur kode. Dapat dikatakan efektif karena siswa dapat dengan mudah memahami materi, pembelajaran yang berlangsung komunikatif dan siswa yang aktif dalam proses pembelajaran. Namun demikian, perlu diperhatikan bahwa penggunaan campur kode perlu dilakukan batasan agar siswa tidak menyimpang dari materi serta kemampuan berbahasa Indonesia siswa berkembang.

Guru perlu melakukan kendali dalam proses pembelajaran bahasa Indonesia agar dapat meminimalisir penggunaan campur kode. Sesuai dengan pendapat Wardaugh (2006:305) bahwa guru memiliki hak khusus dan kekuatan untuk mengontrol apa yang terjadi di dalam kelas karena guru yang lebih banyak berbicara dan guru yang mengatur jalannya proses pembelajaran.

Hasil penelitian ini memberi gambaran mengenai situasi terkini penggunaan bahasa dalam proses pembelajaran bahasa Indonesia. Gambaran tersebut dapat digunakan sebagai pertimbangan dalam membuat strategi dan metode pembelajaran bahasa Indonesia dengan memperhatikan situasi dan kondisi siswa. Harapannya dengan metode dan strategi tersebut dapat meminimalisir penggunaan campur kode dalam proses pembelajaran bahasa Indonesia.

\section{SIMPULAN}

Bentuk campur kode yang terjadi dalam dalam pembelajaran Bahasa Indonesia di SMK Negeri 1 Banyumas terdiri atas (1) campur ko-de penyisipan kata, (2) campur kode penyisipan frase, (3) campur kode penyisipan klausa, (4) campur kode penyisipan pengulangan kata, dan (5) campur kode penyisipan ungkapan. Faktor penyebab terjadinya campur kode dalam pembelajaran Bahasa Indonesia Negeri 1 Banyumas, yaitu: (1) berubahnya situasi, (2) ingin menjelas- 
kan sesuatu, dan (3) menjalin keakraban antara guru dan siswa.

Penggunaan bahasa yang tepat dapat mendukung pembelajaran yang efektif dan komunikatif. Baik guru dan siswa harus pandai dalam menyikapi penggunaan bahasa di kelas. Guru harus bisa mengendalikan siswa agar tidak menyimpang dari materi dan tetap menggunakan bahasa Indonesia sebagai bahasa utama sehingga siswa dapat memahami materi yang disampaikan oleh guru, keterampilan dan kompetensi linguistik bahasa Indonesia siswa berkembang. Penggunaan bahasa daerah yang berlebihan dalam pem-

\section{DAFTAR PUSTAKA}

Ariffin, K. dan Husin, M. S. 2011. Code-switching and Code-mixing of English and Bahasa Malaysia in Content-Based Classrooms: Frequency and Attitudes. The Linguistics Journal, 5(1): 220-247.

Azhar, I.N. 2011. Sosiolinguistik Teori dan Praktik. Surabaya: Lima-lima Jaya.

Ayemoni, M.O. 2006. Code-switching and code mixing: Style of Language use in childhood in Yoruba speech community. Nordic Journal of African Studies, 15(1): 90-99.

Damayanti, Welsi. 2016. Analisis Penggunaan Multilingual Anak Tingkat Sekolah Dasar di Lingkungan Gang Siti Mardiah Cibaduyut Bandung (Studi Sosiolinguistik). Jurnal Gramatika, 1(1), 100-110.

Devi, M. H. R. 2013. Alih Kode dan Campur Kode dalam Kegiatan Belajar Mengajar di SMK Negeri 1 Kalibagor Kecamatan Kalibagor Kabupaten Banyumas Tahun Pelajaran 20122013. Skripsi Universitas Muhammadiyah Purwokerto.

Herawati. 2016. Campur Kode dalam Peristiwa Komunikasi di Lingkungan Sekolah SMA Negeri 1 Kabangka. Jurnal Humanika, 1(16): 1-15.

Hestiyana. 2013. Campur Kode Bahasa Indonesia dan Bahasa Banjar pada Status Facebook Kalangan Remaja Kota Banjarmasin. Undas Jurnal Hasil Penelitian Bahasa dan Sastra, 9(1): 15-28.

Hossain dan Bar 2015. A Sase Study in Code-Mixing among Jahangirnagar University Students. International Journal of English and Literature. 6 (7): 123-139.

Indra, I. B. K. (2008a). Faktor Pendukung Terjadinya Campur Kode dalam Pementasan Drama Gong di Bali. Aksara, XIX (31), 35 - 43.

Kridalaksana, H. (2011). Kamus Linguistik: Edisi Keempat. Jakarta: Gramedia Pustaka Utama. belajaran dapat mengurangi kewibawaan bahasa Indonesia sebagai pengantar utama di sekolah.

\section{UCAPAN TERIMA KASIH}

Ucapan terima kasih diberikan kepada seluruh guru yang telah bersedia menjadi sumber data penelitian selama pengumpulan data. Selanjutnya, ucapan terima kasih diberikan pula kepada mitra bestari (reviewers)yang telah memberikan saran, kritik, dan rekomendasi perbaikan artikel ini.

Krishnasamy, K. 2015. Code mixing among TamilEnglish Bilingual Children. International Journal of Social Science and Humanity. 5 (9): 788-792.

Maemunah, E. 2013. Campur Kode Dalam Ala Chef Bersama Farrah Quinn. Jala Bahasa; Jurnal Ilmiah Kebahasaan, 9(1): 1-15.

Mahsun. (2012). Metode Penelitian Bahasa: Tahapan Srategi, Metode, dan Tekniknya. Jakarta: Rajawali Pers.

Muysken, P. 2000. The Study of Code Mixing. New York: Cambridge: University Press.

Nirmala, V. 2013. Alih Kode dan Campur Kode Tuturan Tukul Arwana pada Acara Bukan Empat Mata. Ranah, 2(2): 10-23.

Nurlaila, M. 2016. Pengaruh Bahasa Daerah (Ciacia) terhadap Perkembangan Bahasa Indonesia Anak Usia 2 Sampai 6 Tahun di Desa Holimombo Jaya. Retorika: Jurnal Bahasa, Sastra, dan Pengajarannya, 9(2): 90-163.

Rulyandi., Rohmadi, M., dan Sulistyo, A.T. 2014. Alih Kode dan Campur Kode dalam Pembelajaran Bahasa Indonesia di SMA. Jurnal Paedogigia, 17 (1): 27-39.

Saddhono, K. 2012. Pengantar Sosiolinguistik(Teori dan Konsep Dasar). Surakarta: Universitas Sebelas Maret Press.

Saddhono, K., dan Rohmadi, M. 2014. A Sociolinguistics Study on the Use of the Javanese Language in the Learning Process in Primary Schools in Surakarta, Central Java, Indonesia. International Education Studies, 7(6): 25-30.

Sari, N.W.E. dan Wedasuwari, I.A.M. 2014. Pilihan Bahasa Siswa Kelas XI IPA 2 SMA (SLUA) 1 Saras wati Denpasar. Jurnal Bakti Saraswati, 3(2): 40-47.

Sumarsih, Siregar, M., Bahri, S., \& Sanjaya, D. 2014. Code Switching and Code Mixing in Indonesia: Study in Sociolinguistics. English 
Language and Literature Studies, Canadian Center of Science and Education, 4(1): 77-92.

Susmita, N. 2015. Alih Kode dan Campur Kode dalam Pembelajran Bahasa Indonesia di SMP Negeri 12 Kerinci. Jurnal Penelitian Universitas Jambi seri Humaniora, 17(2): 87-98.

Suwandi, S. 2010. Serba Linguistik (Mengupas Pelbagai Praktik Berbahasa). Surakarta: UNS
Press.

Wang, D., dan Kirkpatrick, A. 2012. Code Choice in The Chinese as a Foreign Language Class room. Multilingual Education, 2(3): 1-18.

Wardaugh, R. dan Fuller, J. M. 2015. An Introduction to Sociolinguistics: Seventh Edition. Oxford: Wiley Blackwell. 